\title{
Evaluation of the Children Friendly School Policy Implementation in the Depok City
}

\author{
$1^{\text {st Jasra Putra }}$ \\ Unviersitas Negeri Jakarta \\ Indonesia \\ jasraputra_mp16s3@mahasiswa.unj.ac.id
}

\author{
$2^{\text {nd }}$ Eliana Sari \\ Unviersitas Negeri Jakarta \\ Indonesia
}

\author{
$3^{\text {rd }}$ Ma'ruf Akbar \\ Unviersitas Negeri Jakarta \\ Indonesia
}

\begin{abstract}
The purpose of the study is first, evaluating the congruency between expectations with the implementation of the Child Friendly School program in the Depok city since the stages of antecedent, the transaction implementation and the outcomes of the Child Friendly School program at the school level. Second, see the contingency between antecedents with transactions, antecedents with outcomes and transactions with outcomes in the implementation of the Child Friendly School program at Depok city level. Using Stake's contienance evaluation model. Data were collected by interviewing policy makers, field observations to 31 (thirty one) schools in the Depok City and taking evaluation data to 183 (one hundred eighty three) respondents consisting of school principals, teachers, education personnel, students and parents of students. School selection is done by simple random sampling as well as the selection of teachers, education personnel, students and parents of students is done by random random sampling. The results of the evaluation can be concluded that the Child Friendly School program in the Depok city has not run efficiently and effectively. Program implementation at the antecedent level is lacking and has a high gap with expectations, at the transaction level it is less and has a gap with expectations, but at the level of good outcomes and has reached expectations. Contingency implementation is antecedent with positive transactions, antecedent with negative outcomes, and antecedent with negative outcomes. Child Friendly perceived in school is not only influenced by the intervention of the Child Friendly School program, but there are intervening variables.
\end{abstract}

Keywords-Evaluation, Children, Friendly

\section{INTRODUCTION}

(Gaffney, 2019) Bullying remains a ubiquitous problem internationally and isan important topic for effective intervention and empiricalresearch. Bullying is characterized by three core elements, namely (1) an intention to harm; (2) repetitive in nature; and(3) a clear power imbalance between perpetrator and victim. ${ }^{1}$ In addition to bullying, other forms of irregularities in schools can be in the form of punishment with violence, violence between students, brawls between students, sexual violence, pregnancy and impregnation.

(Stevens, 2001) Program intervention is needed in this case to provide direction for the better. Although the use of good model programmes is encouraged within health promotion as a way of heightening the quality of prevention efforts, one must not minimalize the process of programme adaptation. On the one hand, merely copying or replicating the model programme could result in a concept that works in Norwegian schools in Bergen, but affects other educational settings in a different way; on the other hand, the adaptation process includes the problem of programme fidelity and modification of the intervention to the new setting, which may change the core features of the programme. Outlined effective school interventions against bullying, including taking a holistic approach, developing social and emotional competencies, and learning the right way to respond to bullying behavior, providing support and professional development of teachers and ensuring systematic program implementation and evaluation.

Violence is a common enemy, international education institutions ensure that they are free from violence, both violence from teachers against students, and violence between students. The school system creates school regulations, rules and management systems that free schools from violence. The effect of violence is very dangerous for the future of children, the future of children is part of the future of the nation and nation. The state must be present to create schools that are friendly to children, free from violence.

Child Friendly Schools (SRA) are the rights of students that must be fulfilled by educators, education staff, government, business and community including parents. This right is a form of protection of children in obtaining education and teaching including protection from acts of violence as stated in Law 352014 concerning Child Protection

This study was limited by evaluating the implementation of the Child Friendly School (SRA) 
policy in the city of Depok. An evaluation of Depok City Government's policy on Child Friendly Schools (SRA) with sub focus includes input, (antecedent), process (transaction) and results (outcome). The sub focus of this research is divided into three stages, the first, stage is related to the input (antecedent) covering the basic policy and philosophical normative policies, planning in the form of material and program stages, strategies, availability of Human Resources, and the budget. The two processes (transaction) which include legal basis, training, guidance, declaration, organization arrangement, coordination, supervision, involvement of all parties, the roles and contributions of the parties, responsibilities, physical development of the school, provision of the school environment, availability of canteen facilities and friendly school inventory children, the implementation of childfriendly learning. And the third outcome (outcome) of child-friendly schools in the form of equality of children in service in schools, school guarantees that there is no violence in the treatment of children and all school policies are oriented to the best interests of children.

\section{THE RESEARCH FINDINGS}

The limitation of this research is the evaluation of the implementation of the Child Friendly School program based on the stakeholder evaluation model of the stages of input (antecedent), process (transaction) and results (outcomes). The formulation of the problem is as follows: the first, how to prepare (antecedent) Child Friendly School programs which include (a) basic policies; (b) program planning; (c) SRA program strategies; (d) availability of Human Resources; (e) Human Resources competencies; (f) Budget.

The second, what is the process (transaction) for the implementation of the Child Friendly School program at the City and Education Unit level which includes (a) the availability of a legal basis; (b) Training / Worksheets / Equalization of Perception about Child Friendly Schools; (c) publishing a Child Friendly School guide; (d) implementation of the Declaration of Child Friendly Schools; (e) arrangement of a Child Friendly School group; (f) coordinating the organization of Child Friendly Schools; (g) conducting supervision; (h) involvement of students / students / community parents in the program (i) the role and contribution of parents of students / students / community in the program (j) the responsibilities of parents of students / students / community in the program (k) the development of child-based schools; (l) childbased school environment; (m) child-oriented health canteen; (n) children's standard desk and learning (o) child-friendly learning.

The third, how the outcomes consist of (a) schools that do not differentiate children in the form of gender, social status and social functions. (b) schools guarantee zero violence (c) school activities are oriented to the best interests of children.

Owen (Owen, 2006) is said Evaluation should be seen as a process of knowledge production, which rests on the use of rigorous empirical enquiry. Evaluation will be worth the investment of time and money if the knowledge produced is reliable, responsive to the needs of policy and program stakeholders, and can be applied by these stakeholders.

(Stufflebeam, 2002) Evaluation can be a frustrating business; one major source of frustration is its potential ineffectuality. That is to say it often fails to enter the decision making process at the right time, saying useful things to the right people such that positive contributions to development can be made that do justice to the complex and contradictory experience change can involve.

(Moran, Rein, \& Goodin, 2006) The essence of evaluation is photographing the advantages and disadvantages of an object. The object in question is a unit that is used as a program, as a product policy. These processes have their corollaries in public policy, both as a practical activity and a Weld of study. Policy makers compare current problems to previous ones, networking with others both in their own and in other jurisdictions. By the same token, we might think of the collective process of agenda setting as one in which a polity learns as much as decides what it wants, and implementation as the process by which agencies and employees learn how to deliver it.

The primary stage to program development is the conceptual foundation. Once this has been established, the program theory can be used to develop outcome and intermediate goals (Sharpe, 2011) (Glyn Sharpe, Journal) Program set to achieve goals, values and directed practice. the program is determined by policy.

The policy making process is a political process that takes place in the stages of political policy making, ie this political activity is explained as a policy making process, and visualized as a series of interdependent stages, arranged according to time sequence, such as agenda setting, policy formulation, policy adoption, policy implementation, and policy assessment. Policy evaluation is seen as a functional activity, not only carried out at the final stage but to the entire policy process. (Dunn, 2000).

The evaluation model that the researchers chose in order to evaluate government policy regarding the implementation of the Child Friendly School (SRA) policy in the city of Depok is a model that was first developed by (Stake, 2004) The Evaluation called the 'Countenance' model, focusing on assessment.

The stages of conducting research in the countenance model developed by Stake's consist of three stages, namely; inputs (antecedents), processes (transactions), and results (outcomes). Each stage is divided into two stages, namely description (description) and decision / judgment (judgment) that is confirmed by the target which is a measure of the effectiveness of a program that is implemented.

\section{CONCLUSION}

Based on the results of research evaluating the implementation of the policy of Child Friendly Schools in the City of Depok, it can be concluded that the implementation of the Child Friendly Schools program in Depok City has not been running effectively and efficiently. Some components in the implementation of the program there is a congruence between the intended purpose (intended) and the actual factual conditions 
(observation). In fact, the contingency between antecedents, transactions and outcames shows that the effectiveness of the implementation of the program at the antecedent stage affects transactions and also affects outcames. More specifically the conclusions of the results of this study can be explained based on the unit analysis evaluated as follows:

\section{A. Anteceden}

The antecedent evaluation phase of the implementation of the Child Friendly School program in Depok, all aspects evaluated in this unit of analysis do not meet the standards outlined, that is very good, in the findings, the data obtained in the field (observation) is lacking. The organizers in this case the Depok City Education Office and the Depok City Community and Family Empowerment Protection Agency (PAPMK) have not been optimal in building the foundation of the Child Friendly School program in Depok City. Development programs that are still not optimal include; philosophical strengthening, regulative programs, program strategy planning, strengthening and fostering Human Resources for organizing and implementing programs and budgeting programs. Especially not yet optimal program strengthening, special budget allocations and human resources (teachers, education personnel, supervisors) trained in child protection perspectives.

\section{B. Transaction}

Transaction evaluation phase of the implementation of the Child Friendly School program in Depok, all aspects evaluated in this unit of analysis do not meet the standards outlined, in the findings, the data obtained is inadequate. The organizers, in this case the Depok City Education Office and the Depok City Community and Family Empowerment Child Protection Office (PAPMK), are less prepared in conceptual, procedural and infrastructure of schools that have child-friendly school standards in Depok. Many Schools do not get a Decree from the City Education Office Depok related to SRA piloting including guidelines owned by the central and regional levels. So that the SRA declaration by the education unit as one of the conditions for implementing the policy has not been fulfilled. The implementation of the SRA policy declaration was marked by the installation of the Child Friendly School brand plank on school buildings. The implementation of the SRA was still a formality, limited to reporting, administrative, and had not achieved substantive matters related to children's rights and the best interests of children.

\section{Outcomes.}

The outcame phase of evaluating the implementation of the Child Friendly School program in Depok City in general the aspects evaluated in the unit analysis have almost all reached the standard outlined, with an average in the unit analysis outcomes category very good. Culture or culture of child-friendly education community in the city of Depok has been created naturally. The equality of service and treatment of children has been created very well, nonviolent action has been embedded into a value that is upheld, and the relationship between parties in the school, leadership with children, teachers with children, school officials with children walking with haromonis there is absolutely no violence in in it, but the school has not involved children in policy making both at the school level and at the City Government level as a form of respect, respect and listening to children's opinions through children's participation.

\section{Countingency.}

Antecedent relationship with positive transactions, thus that antecedents have influenced transactions, antecedent relationships with negative outcomes, meaning that antecedents have no effect on outcomes, as well as the relationship of transactions with negative outcomes, meaning that there is no effect of transactions on outcomes.

Aspects and indicators in the antecedent unit analysis affect aspects and indicators in the unit analysis transaction, but the indicators and aspects of the antecedent unit analysis and transaction do not affect the outcome, so it can be stated that the child-friendly school in Depok City has been realized culturally and naturally, not the results of program interventions.

\section{THE RESEARCH RECOMENDATION}

Based on the conclusions of the evaluation research that has been presented, it can be recommended improvement efforts to improve the implementation of the Child Friendly School policy. In general, Child Friendly Schools need to conduct orientation, simulation, semination, supervision, and compensation, so that the effectiveness and efficiency of policies run optimally. Child friendly culture, fair treatment of children, appreciation of children's problems, and the mainstreaming of the best interests of children in school policies has been very well realized in the education unit in Depok, but the gradual, systematic development of the Child Friendly School program and planned since the antecedent and transaction analysis unit has not been developed properly, the researcher hereby recommends to several parties as follows:

\section{A. Ministry of Women's Empowerment and Child Protection.}

(a). Need to increase the socialization of Law No. 35 of 2014 concerning Child Protection, especially in education units at the primary level. (b). Need to coordinate with the Ministry of Education and Culture related to the implementation of Minister of Women Empowerment and Child Protection Regulation No. 8 of 2014 concerning Child Friendly School Policy. Or the Regulation of the Minister of PPA on the policy of friendly schools needs to be strengthened by the legal umbrella in the form of a Presidential Regulation (Perpres) on Child Friendly Cities, of which of the 24 indicators one of them relates to Child Friendly Schools. (c). It is necessary to conduct an orientation, simulation, and semination to the Department of Education, the Office of Child Protection, Supervisors and School Principals related to the effectiveness and efficiency of Child Friendly Schools.d. The Ministry of PPPA with the Ministry of Education and Culture needs to sit together and update the guidelines and standardization of Child 
Friendly Schools as a reference for supervision by the Office of Education and the Office of Child Protection and School Supervisors in Regencies and Cities in Indonesia.

B. Ministry of Education and Culture.

(a). It is necessary to issue Minister of Education and Culture Regulation to strengthen Minister Regulation PPPA No. 8 of 2014 concerning Child Friendly School Policy. (b). Need to coordinate regularly and be programmed with the Ministry of Women's Empowerment and Child Protection in conjunction with the implementation of the Child Friendly School policy in the education unit. (c). Form an ad hoc committee related to the implementation, coordination and supervision of Child Friendly Schools.

C. Depok City Education Agency.

(a). Need to socialize with regard to the narrative of the importance of the Child Friendly School program to stakeholders, so that the Child Friendly School organizers at the level of the education unit have ideological, philosophical and spiritual strength. (b). Need to ensure that stake holders know and understand the policy of Child Friendly Schools, in this case Law No. 35 of 2014 concerning Child Protection; PPPA Minister Regulation No. 8 of 2014 concerning Child Friendly School Policies; Depok City Regulation Number 15 of 2013 concerning Implementation of Child-Friendly Cities; Decree of the Department of Education and Department of Child Protection for Community and Family Empowerment (PAPMK) of Depok City on the Appointment of Child Friendly Schools. (c). Form an ad hoc committee related to the implementation, coordination and supervision of Child Friendly Schools, which have more specific tasks and functions. (d). A special budget allocation policy is needed to strengthen the Child Friendly School program in the education unit.

D. Child Protection Agency Community and Family Empowerment.

(a). Need to socialize with regard to the narrative of the importance of the Child Friendly School program to stakeholders, so that the Child Friendly School organizers at the level of the education unit have ideological, philosophical and spiritualist strength. (b). Need to ensure that stake holders know and understand the policy of Child Friendly Schools, in this case Law No. 35 of 2014 concerning Child Protection; PPPA Minister Regulation No. 8 of 2014 concerning Child Friendly School Policies; Depok City Regulation Number 15 of 2013 concerning Implementation of Child-Friendly Cities; Decree of the Office of Education and the Office for the Protection of Children Empowering Communities and Families regarding the Appointment of Child Friendly Schools. (c). Strengthening coordination, communication, supervision, and evaluation of the Child Friendly School Task Force established by the Depok City Government on Child Friendly Cities (KLA).

\section{REFERENCES}

[1] Dunn, W. N. (2000). Pengantar Analisis Kebijakan Publik. Yogyakarta: Gadjah Mada Perss.

[2] Gaffney, H. (2019). The Effectiveness of School-Bullying InterventionPrograms Globally: a Meta-analysis. International
Journal of Bullying Prevention Examining, 1, 14-31. doi:https://doi.org/10.1007/s42380-019-0007-4

[3] Moran, M., Rein, M., \& Goodin, R. E. (2006). The Oxford Handbook of Public Policy. New York: Oxford University Press.

[4] Owen, J. M. (2006). Program Evaluation Forms and Approaches. Australia: National Of Library Australia.

[5] Sharpe, G. (2011, November). A Review of Program Theory and Theory-Based Evaluations. American International Journal of Contemporary Research , 1 .

[6] Stake, R. E. (2004). Standards-Based Responsive Evalutaion. London: Sage Publications.

[7] Stevens, V. (2001, June). Anti-bullying intervention at School: aspects of progamme adaptation and critical issues for further programe development. Health Promotion International, Volume 16, 155-167. doi:https://doi.org/10.1093/heapro/16.2.155

[8] Stufflebeam, D. L. (2002). Evaluation Model: Viewpoints on Education and Human Services Evaluation Second Edition. Newyork: Kluwer Academic Plubhiser. 